\title{
Impact of roughness of discontinuities on the behaviour of jointed rock samples
}

\author{
Patrycja Jarczyk ${ }^{1, *}$ \\ ${ }^{1}$ Silesian University of Technology, Faculty of Mining and Geology, Gliwice, Poland
}

\begin{abstract}
The subject of the publication is the behavior of rock samples faulted by individual discontinuities with different roughness under threeaxial compression conditions, with confining pressures up to $30 \mathrm{MPa}$. Samples with discontinuities oriented at angles of $30^{\circ}, 45^{\circ}$ and $60^{\circ}$ in relation to the directions of external loads were prepared for the tests. Before the three-axial compression tests, the discontinuity surfaces were scanned and parameters describing the geometrical structure of these surfaces were determined. It has been shown that the roughness of the discontinuity walls causes a reduction in stiffness and strength. It has also been shown that with the increase of the confining pressure, the strength of the samples increases linearly, and the higher values of the angle at which the discontinuity is oriented corresponds to higher strength.
\end{abstract}

Keywords: roughness, discontinuity, jointed rock samples, triaxial compression, strength, stiffness

\section{Introduction}

Properties and behaviour of discontinuous rock centres depend, inter alia, on the number of discontinuities, the distance between them, their orientation, opening, type and the degree of their filling. The properties of discontinuities depend in particular on the geometrical structure of their walls [4-7]. That structure allows to describe the parameters that characterize the surface. One of them, proposed by Barton [1] and commonly used in geomechanics, is the JRC coefficient - roughness coefficient of the discontinuity wall. This coefficient is determined on the basis of the evaluation of a single profile (Figure 1). The most even, smooth surfaces are assigned JRC values from 0 to 2 , the most uneven, rough from 18 to 20 .

\footnotetext{
*Corresponding author: patrycja.jarczyk@polsl.p1
} 


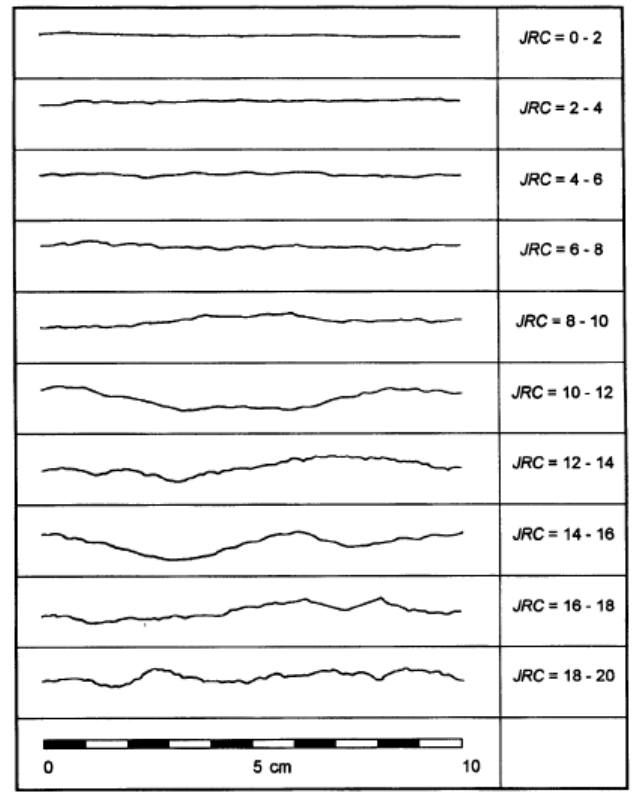

Fig. 1. Profiles of discontinuity wall roughness in rocks according to Barton [1].

Determination of the JRC parameter value is also possible on the basis of the so-called reverse analysis, i.e. based on the results of a direct shear test. The relationship between shear strength and normal stress is determined in accordance with Barton's strength criterion:

$$
\tau_{p}=\sigma_{n} \operatorname{tg}\left(J R C \log \frac{J C S}{\sigma_{n}}+\phi_{r}\right)
$$

in which the limit strength for shear discontinuity $\tau_{p}$ is a function of normal stress $\sigma_{n}$, and one of the parameters is the roughness index JRC. This equation shows the Joint Roughness Coefficient (JCS) of the discontinuity wall and the residual friction angle $\phi_{r}[1,2]$. The JRC parameter value is determined on the basis of that equation and depends on the stress and properties of the rock material and, therefore, loses the features of a geometrical parameter.

In order to describe the geometric structure of discontinuities and the influence of roughness on the behaviour of discontinuous rock centres, the parameters used in the material science and tribology to describe the geometric structure of rough surfaces $[8,9]$ were used in this paper.

\section{Examination of the geometric structure of the surface}

The rock samples tested under three-axial compression were affected by individual discontinuities. The surfaces of these discontinuities had various geometrical structures. Some of them were smooth after being cut with a rotating diamond disc, and others had greater roughness resulting from the bombardment of these surfaces with a stream of quartz sand.

In order to obtain information on the geometrical structure of the surface, the discontinuity walls were scanned using the NJHP Stone Laser Profilometer.

The following parameters which characterize the geometric structure of the surface were determined on the basis of the conducted measurements:

- $\mathbf{S}_{\mathbf{a}}$ - arithmetic mean of the profile ordinates,

- $\mathbf{S}_{\mathbf{q}}$ - quadratic mean of the profile ordinates, 
- $\mathbf{S}_{\mathbf{p}}$ - height of the highest profile elevation,

- $\mathbf{S}_{\mathbf{v}}$ - depth of the lowest profile recess,

- $\mathbf{S}_{\mathbf{t}}-$ total height of the profile,

- $\mathbf{S}_{\mathbf{s k}}$ - profile asymmetry coefficient,

- $\mathbf{S}_{\mathbf{k u}}$ - profile slope factor (kurtosis),

- $\mathbf{S}_{\mathbf{z}}$ - largest height of the profile.

Table 1. Average values of the parameters that characterize the surface obtained for smooth and blasted walls.

\begin{tabular}{|c|c|c|c|c|c|c|c|c|}
\hline & $S_{a}$ & $S_{q}$ & $S_{p}$ & $S_{v}$ & $S_{t}$ & $S_{s k}$ & $S_{k u}$ & $S_{z}$ \\
\cline { 2 - 9 } & $\mathrm{mm}$ & $\mathrm{mm}$ & $\mathrm{mm}$ & $\mathrm{mm}$ & $\mathrm{mm}$ & - & - & $\mathrm{mm}$ \\
\hline $\begin{array}{c}\text { Smooth } \\
\text { surfaces }\end{array}$ & 0.019 & 0.025 & 0.075 & 0.231 & 0.283 & -1.411 & 9.989 & 0.211 \\
\hline $\begin{array}{c}\text { Rough } \\
\text { surfaces }\end{array}$ & 0.087 & 0.110 & 0.322 & 0.520 & 0.842 & -0.486 & 3.422 & 0.686 \\
\hline
\end{tabular}

On the basis of the measurements, it was found that the parameters describing the geometrical structure of blasted discontinuity wall surfaces have three or four times higher values than the parameters of smooth surface discontinuities, except for two of them: asymmetry of height distribution and height distribution kurtosis, which are three times smaller (Table 1). The arithmetic and quadratic means of the profile ordinates and the height of the highest profile elevation are four and a half times higher for rough walls. The differences between the largest elevation and the deepest recess for a given elementary section are three times greater for rough walls, as well as the sum of the heights of the highest profile elevation and the deepest depth of the profile for a given elementary section. The depth of the lowest recess is slightly more than two times higher for rough walls (Table 1).

Those measurements show that the degree of roughness of discontinuity walls which were subjected to sandblasting is significant, which allows the description of further tests with regard to the division of models into those with smooth and rough walls.

\section{Conventional tri-axial compression tests of rock samples damaged by discontinuities}

As a result of conventional tri-axial compression laboratory tests on rock samples damaged by individual discontinuities, differential stress characteristics $\left(\sigma_{1}-\sigma_{3}\right)$ and vertical displacement $\left(\lambda_{z}\right)$ values were obtained. Depending on the angle at which the discontinuity was oriented, the conclusion of the test was determined by an occurrence of material macrocracking or by a vertical displacement. In the case of samples with $60^{\circ}$ discontinuities, laboratory tests were terminated when a macro-cracking occurred in the rock material. In the case of samples with $30^{\circ}$ and $45^{\circ}$ discontinuities, no macro-cracks occurred so laboratory tests were terminated when the vertical displacement reached a value of about $2.5 \mathrm{~mm}$. The following values which characterize the behaviour of rock samples were determined on the basis of the obtained characteristics:

- linear longitudinal stiffness coefficient (Figure 2), i.e. the directional coefficient of the linear parts of the characteristics, 


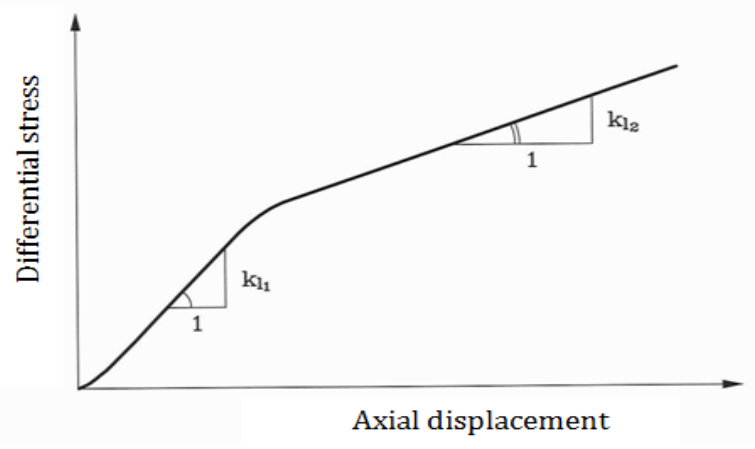

Fig. 2. The method of determining linear stiffness coefficients from bimodal characteristics.

- the longitudinal stiffness coefficient corresponding to the strength limit (Figure 3), i.e. the secant directional coefficient connecting the origin of the coordinate system to the top of the curve,

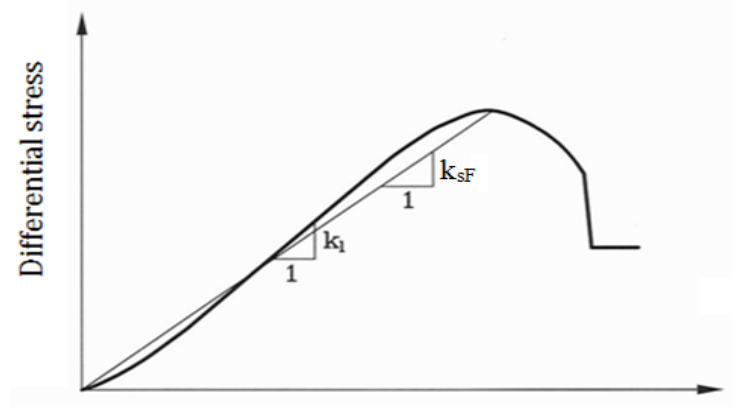

Axial displacement

Fig. 3. The method of determining the linear and secant stiffness coefficients from the characteristics of samples that have cracked.

- $\quad$ values of stress and strain at the slip point (i.e. the point of change of slope of the characteristic stress - displacement),

- values of stresses at displacements from $0.5 \mathrm{~mm}$ to $2.5 \mathrm{~mm}$,

- limit values of stresses in cases when the strength of the rock material has been exceeded and the sample has been subjected to macro-cracking,

- maximum values of stresses in cases where rock macro-cracking did not occur

The tests allowed to obtain information on the impact of discontinuity wall roughness on the behaviour of simple models of the cracked rock medium under tri-axial compression.

The deformation process of samples with smooth wall cracks oriented at $30^{\circ}$ and $45^{\circ}$ relative angles to the vertical axis of the sample is bimodal and the so-called slip points occur in the characteristics of the differential stress $\left(\sigma_{1}-\sigma_{3}\right)$ and vertical displacement $\left(\lambda_{z}\right)$ (Fig. $4 \mathrm{a}$, b). This is the point where the characteristics of the slope change. Below the slip point, the sample has a high stiffness determined by small deformability of the rock material. Above this point, slip of one part of the sample dominates over the other (the so-called intermittent slip). It is associated with temporary increases and decreases in differential stress due to abrupt movement of one part of the sample relative to the other $[3,7,9]$. 


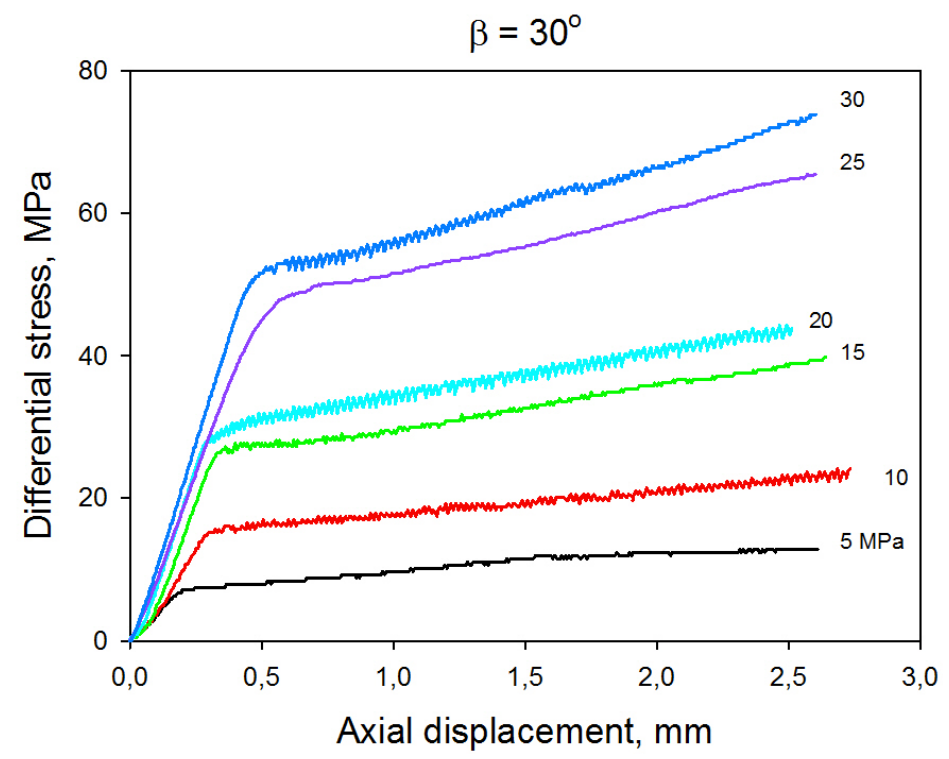

a)

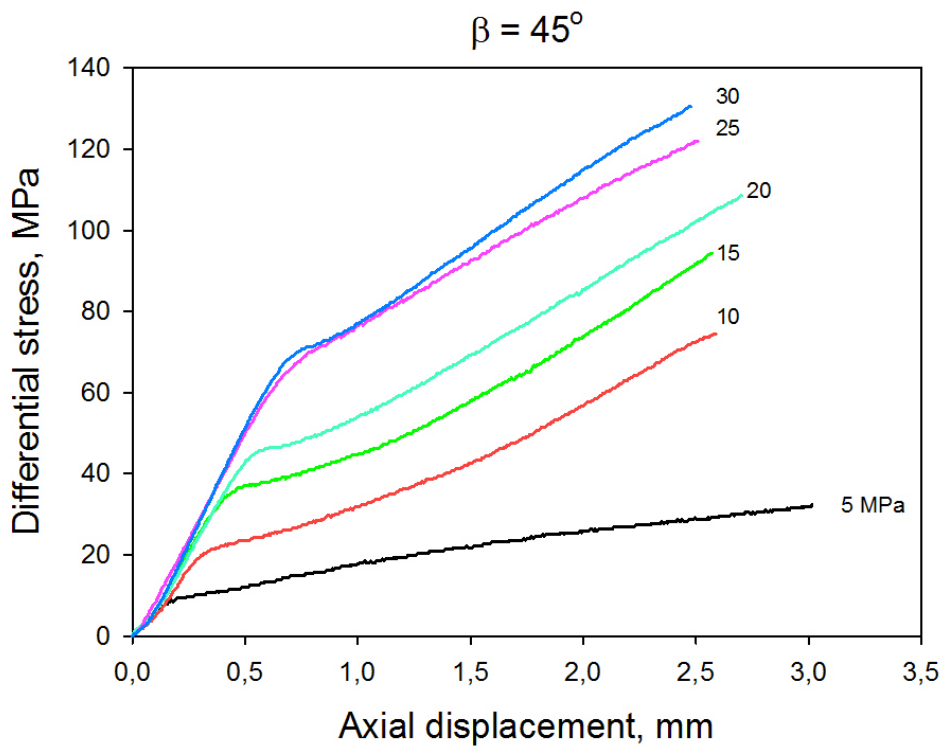

b)

Figure 4. Differential stress $\left(\sigma_{1}-\sigma_{3}\right)$ - axial displacement $\left(\lambda_{z}\right)$ characteristics for samples cut at a) $30^{\circ}$ and b) $45^{\circ}$ angles.

Slip on the plane of the crack oriented vertically to the sample at an angle of $60^{\circ}$ is negligible; deformation is dominated by continuous deformation of the rock material. Characteristics of differential stress - vertical displacement of samples with a $60^{\circ}$ fracture have the same form as the characteristics of intact rock samples (Figure 5). 


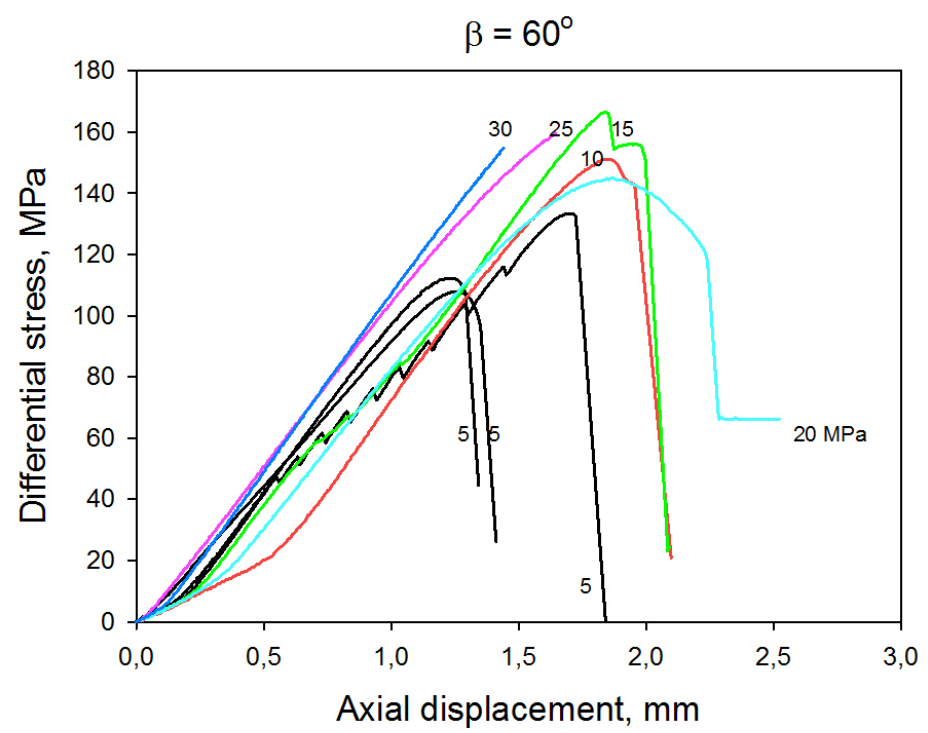

Fig. 5. Differential stress $\left(\sigma_{1}-\sigma_{3}\right)$ - axial displacement $\left(\lambda_{z}\right)$ characteristics for samples cut at $60^{\circ}$ angle.

The process of deformation of samples weakened by a $60^{\circ}$ fracture results in an excess of the limit strength of the rock material and an occurrence of shear macro-cracks, which usually appear in three-axially compressed samples of intact rock material (Figures 5 and $6 \mathrm{c}$ ).

In contrast to the specimens with stress - displacement characteristics typical for smooth wall cracks, which consist of two linear parts separated by a slip point, stress - displacement characteristics of the samples with rough walls discontinuities are significantly non-linear, which reflects the decrease of roughness and the increase of displacement of the walls caused by their friction (fig. 6).

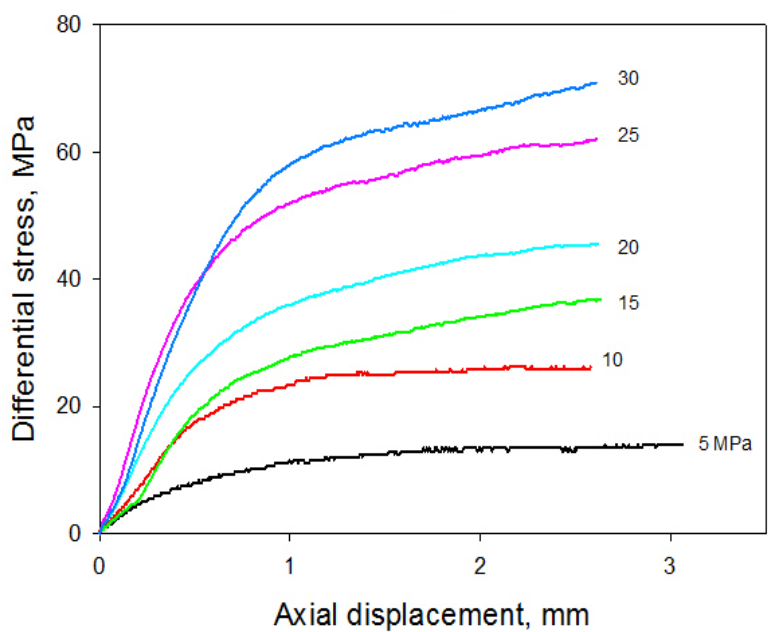

a) 


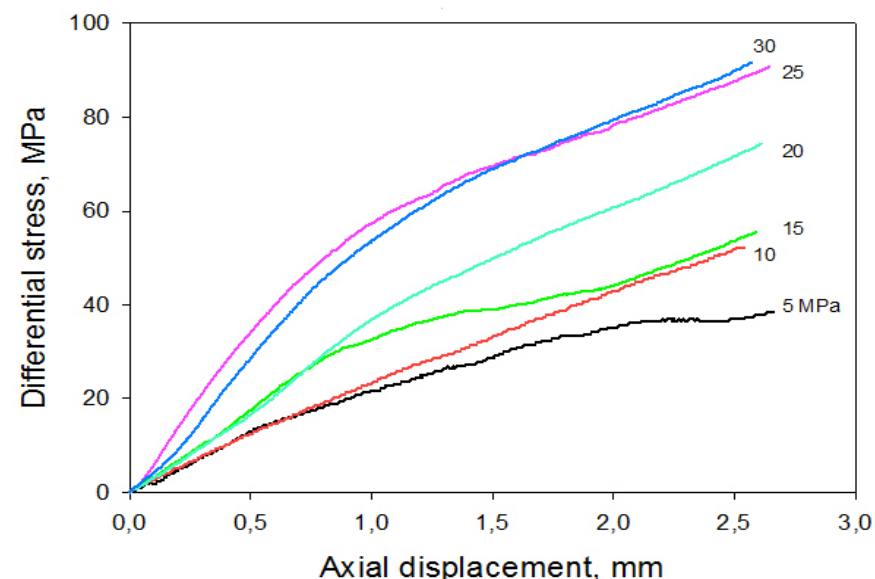

b)

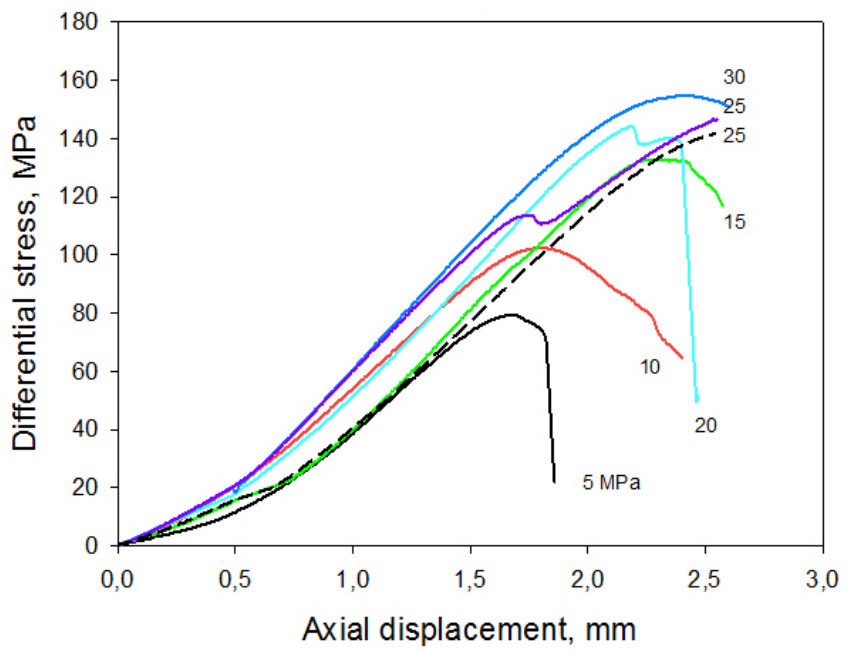

c)

Fig. 6. Differential stress $\left(\sigma_{1}-\sigma_{3}\right)$ - vertical displacement $\left(\lambda_{z}\right)$ characteristics for samples with rough discontinuity walls cut at angles of a) $30^{\circ}$, b) $45^{\circ}$ and c) $60^{\circ}$.

As in the case of samples with smooth wall cracks, the strength of rough wall crack samples increased linearly with the increase of the confining pressure. However, unlike those samples, the strength growth rate for the $30^{\circ}$ and $45^{\circ}$ orientation was the same (Fig. 7). 


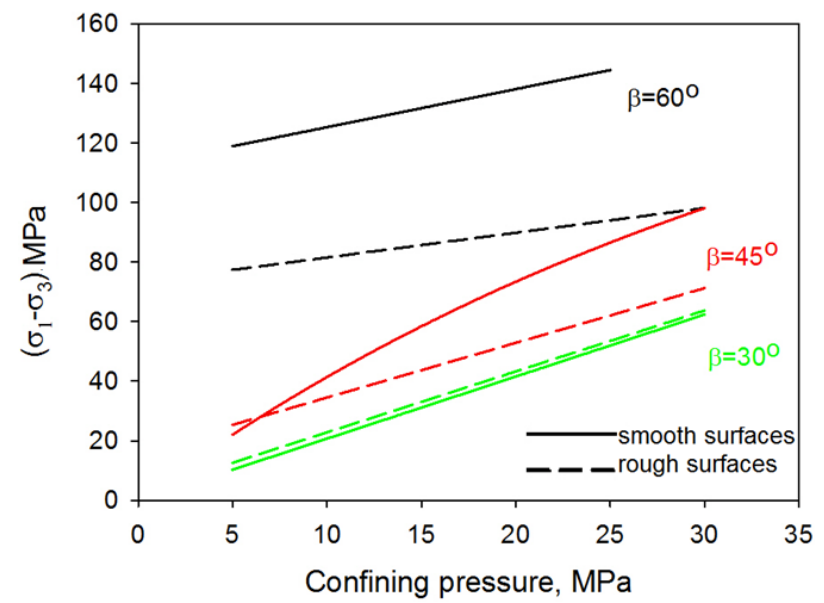

Fig. 7. Effect of orientation of discontinuities and roughness of discontinuous walls on strength.

However, the roughness of discontinuity walls has a significant influence on the longitudinal stiffness of the samples in the first stage of the deformation process, i.e. in the non-slip stage.

In the case of samples with a $30^{\circ}$ fracture at this stage, the longitudinal stiffness coefficient (k11) of the rough wall discontinuity samples ranged from $35 \%$ (for the confining pressure of $5 \mathrm{MPa}$ ) to about $50 \%$ (for the confining pressure of $20 \mathrm{MPa}$ ) less than the stiffness coefficient of samples with smooth wall discontinuities. In the second stage, where the deformation process is dominated by the slipping of discontinuity walls in relation to each other, values of the longitudinal stiffness coefficient $(\mathrm{k} 12)$ for both smooth and rough wall were almost the same and very small, less than $10 \mathrm{MPa} / \mathrm{mm}$ at the confining pressures up to $30 \mathrm{MPa}$.

The values of the longitudinal stiffness coefficient increase significantly with the increase of the confining pressure, while the rate of this increase is greater in the case of samples with smooth wall discontinuities.

Higher inclination angles of the discontinuity with respect to the vertical axis of the sample correspond to greater longitudinal stiffness of the sample (Figure 8).

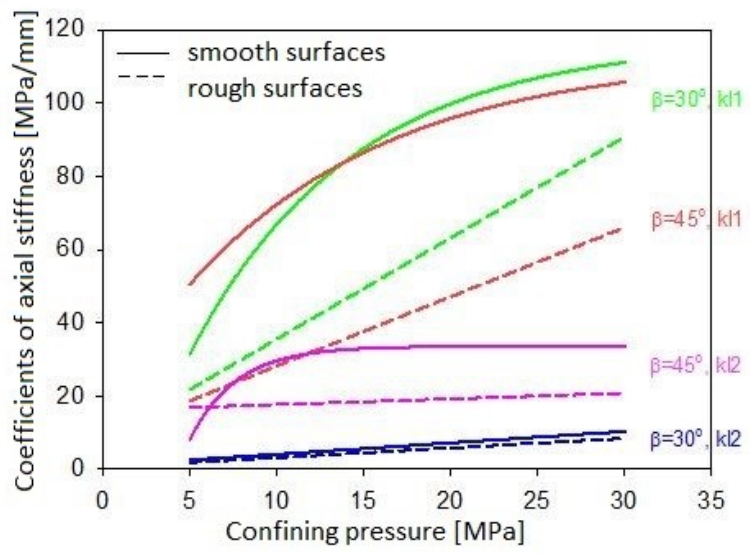

Fig. 8. Effect of confining pressure, discontinuity orientation $\left(30^{\circ}, 45^{\circ}\right)$ and roughness of discontinuity walls on longitudinal stiffness of samples.

Samples with discontinuities oriented at the angle of $60^{\circ}$ were destroyed (macro-cracking 
of the rock material), which allowed to determine their secant stiffness coefficients corresponding to the strength limit (ks). The largest values, equal to $92 \mathrm{MPa} / \mathrm{mm}$, corresponded to the pressure of $5 \mathrm{MPa}$ and decreased to $78 \mathrm{MPa} / \mathrm{mm}$ at the pressure of 20 $\mathrm{MPa}$. In the case of samples with rough walls, the tendency was reversed; the smallest value of this coefficient, equal to $47 \mathrm{MPa} / \mathrm{mm}$, was noted at the pressure of $5 \mathrm{MPa}$, and the highest, equal to $66 \mathrm{MPa} / \mathrm{mm}$, at the pressure of $20 \mathrm{MPa}$ (Fig. 9).

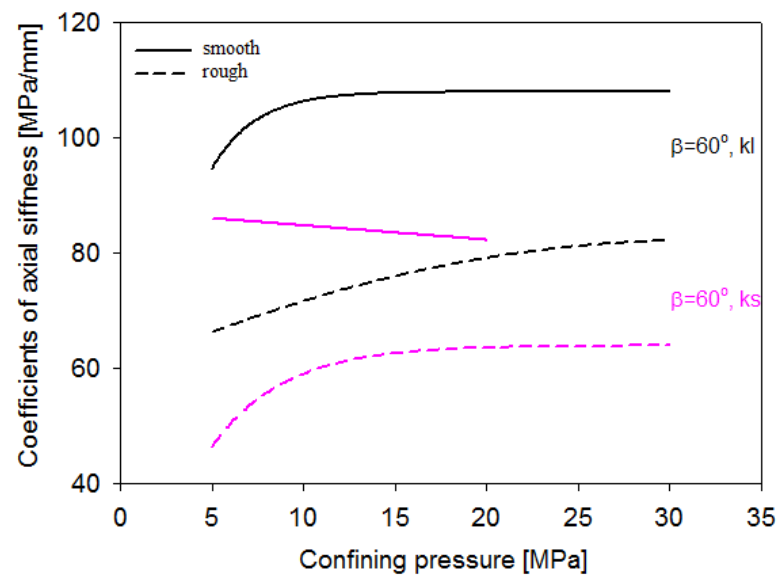

Fig. 9. Effect of confining pressure and roughness of discontinuity walls on longitudinal stiffness of samples affected by $60^{\circ}$ angle discontinuities.

\section{Summary}

Summarizing the results of the tests on rock samples damaged by singular discontinuities which were subjected to tri-axial compression, it was found that in many cases the roughness of the discontinuity walls causes a reduction in strength. The largest decrease is observed at the most-inclined discontinuities $\left(60^{\circ}\right)$, smaller at the $45^{\circ}$ orientation, while at $30^{\circ}$ the roughness virtually does not affect the strength (Fig. 7).

The roughness of the discontinuity walls has a big influence on the longitudinal stiffness of the samples in the pre-slipping stage. At this stage, in the case of samples with a $30^{\circ}$ fracture, the longitudinal stiffness coefficient (k11) of rough wall discontinuities was from approx. $35 \%$ to approx. $50 \%$ smaller than the stiffness coefficient of the samples with smooth wall discontinuities. At the stage where the slipping of discontinuity walls dominates the movement and with the same orientation of discontinuities, the values of the longitudinal stiffness coefficient $(\mathrm{k} 12)$ for samples with smooth and rough discontinuity walls were almost the same (Fig. 8).

It was found that the strength increases with the increase of the confining pressure. Higher angles at which the discontinuity is oriented towards the axis of the sample correspond to higher strength. The rate of strength increase is greatest for samples with discontinuities oriented at the smallest angle $\left(30^{\circ}\right)$ and decreases with the increase of this angle.

The values of the longitudinal stiffness coefficient increase significantly with the increase of the confining pressure, while the rate of this increase is even greater in the case of samples with smooth wall discontinuities.

The values of linear and secant stiffness coefficients for samples with smooth walls discontinuities oriented at the angle of $60^{\circ}$ in relation to the vertical axis of the sample were larger by approx. 50\% than in the case of samples with rough wall discontinuities (Figure 9). 


\section{References}

1. Barton N. R.: Review of a new shear strength criterion for rock joints. Engng. Geol., Vol. 7, 287-332 (1973)

2. Barton N. and Choubey V.: The shear strength of rock joints in theory and practice. Rock Mechanics, No. 1-2, 1-54 (1977)

3. Brown E. T.: Modes of failure in jointed rock masses. In: Proceedings of the Second Congress of the ISRM, Beograd, Vol. 2, 293-298 (1970)

4. Ge Y. F. et al. A new representation method for three-dimensional joint roughness coefficient of rock joint. Chinese Journal of Rock Mechanics and Engineering. 31, 25082517 (2012).

5. Ge Y. F., Kulatilake P. H. S. W., Tang H. M. \& Xiong C. R. Investigation of natural rock joint roughness. Computers and Geotechnics. 55, 290-305 (2014)

6. Kwaśniewski M., Wang J.-A.: O fraktalnym charakterze powierzchni ścianek spękań w skałach. Wykład na XVIII Zimowej Szkole Mechaniki Górotworu, Szklarska Poręba (marzec 1995)

7. Kwaśniewski M., Wang J.-A.: Struktura geometryczna powierzchni i zachowanie się nieciągłości w skałach przy ścinaniu. Wykład na XXI Zimowej Szkole Mechaniki Górotworu, Zakopane (marzec 1998)

8. Lawrowski Z.: Tribologia. Tarcie, zużycie i smarowanie. Wydawnictwo Naukowe PWN, Warszawa (1993)

9. Singh M., Rao K. S. and Ramamurthy T.: Strength and deformational behavior of a jointed rock mass. Rock Mech. Rock Engng., Vol. 35, No. 1, 45-64 (2002) 